\title{
A FOTOGRAFIA DO JARDIM DE INVERNO: BARTHES, FRAGMENTO, FOTOGRAFIA
}

Ana Martins Marques*

RESUMO: Este texto se volta para a junção de texto e imagem fotográfica na obra de Roland Barthes. A partir, sobretudo, de três livros do autor - $O$ império dos signos, Roland Barthes por Roland Barthes e A câmara clara -, buscou-se investigar o modo como o autor conecta escrita autobiográfica e fotografia, num dispositivo híbrido, fragmentário, que coloca em questão não apenas a relação entre texto e imagem, entre escrita de si e imagem de si, mas também a própria prática do livro.

PALAVRAS-CHAVE: Roland Barthes; fotografia; fragmento; autobiografia.

\author{
*anamartins.bh@gmail.com \\ Doutora em Literatura Comparada pela UFMG. É autora dos livros de \\ poesia O livro das semelhanças (2015), $A$ arte das armadilhas (2011)
e A vida submarina (2009).
}

RÉSUME: Ce texte se tourne vers la jonction entre le texte et I'image photographique chez Roland Barthes. À partir, sourtout, de trois livres de l'auteur - L'empire des signes, Roland Barthes par Roland Barthes et La chambre claire - nous avons enquêté sur la façon dont l'auteur relie l'écriture autobiographique et la photographie, dans un dispositif hybride, fragmentaire, qui me en question non seulement la relation entre le texte et l'image, entre l'écriture de soi-même et l'image de soi-même, mais aussi la propre pratique du livre.

MOTS-CLÉS: Roland Barthes; photographie; fragment autobiographie 
1. "Este conferencista ocidental, quando é citado pelo Kobé com os olhos alongados, a

pupila enegrecida pela tipografia nipônica" BARTHES. O império

dos signos, p. 121.
Publicado em 1970, O império dos signos é o primeiro livro de Barthes a associar relato pessoal e emprego da fotografia. Composto por uma série de textos que giram em torno do Japão - entendido, segundo se lê no primeiro ensaio do livro, como um conjunto de traços que formam um "sistema" -, O império dos signos incorpora um número considerável de imagens - reproduções de estampas e gravuras japonesas, um mapa de Tóquio, recortes de jornal, fotos coloridas e em preto e branco, retratos -, acompanhadas de legendas e comentários justapostos, muitas vezes reproduções da escrita manuscrita. Também encontramos aí um retrato do próprio Barthes, em um anúncio de sua conferência, no qual o "conferencista ocidental" aparece "japonesado, com os olhos alongados, a pupila enegrecida pela tipografia nipônica”. ${ }^{1}$

Que a primeira aparição de uma fotografia do autor no interior do texto seja a de um retrato/máscara, que o mostra metamorfoseado, de certa forma "traduzido" pelo filtro de outra cultura, e que esse retrato venha ainda acompanhado da referência a si mesmo como um outro - "o conferencista ocidental" - é bastante ilustrativo de como, na obra de Barthes, o autobiográfico aparece, sempre, como problema. O império dos signos inaugura, assim, na obra barthesiana, a prática da escrita de si marcada pelo fragmento e pelo recurso à fotografia, uma experiência peculiar de junção entre
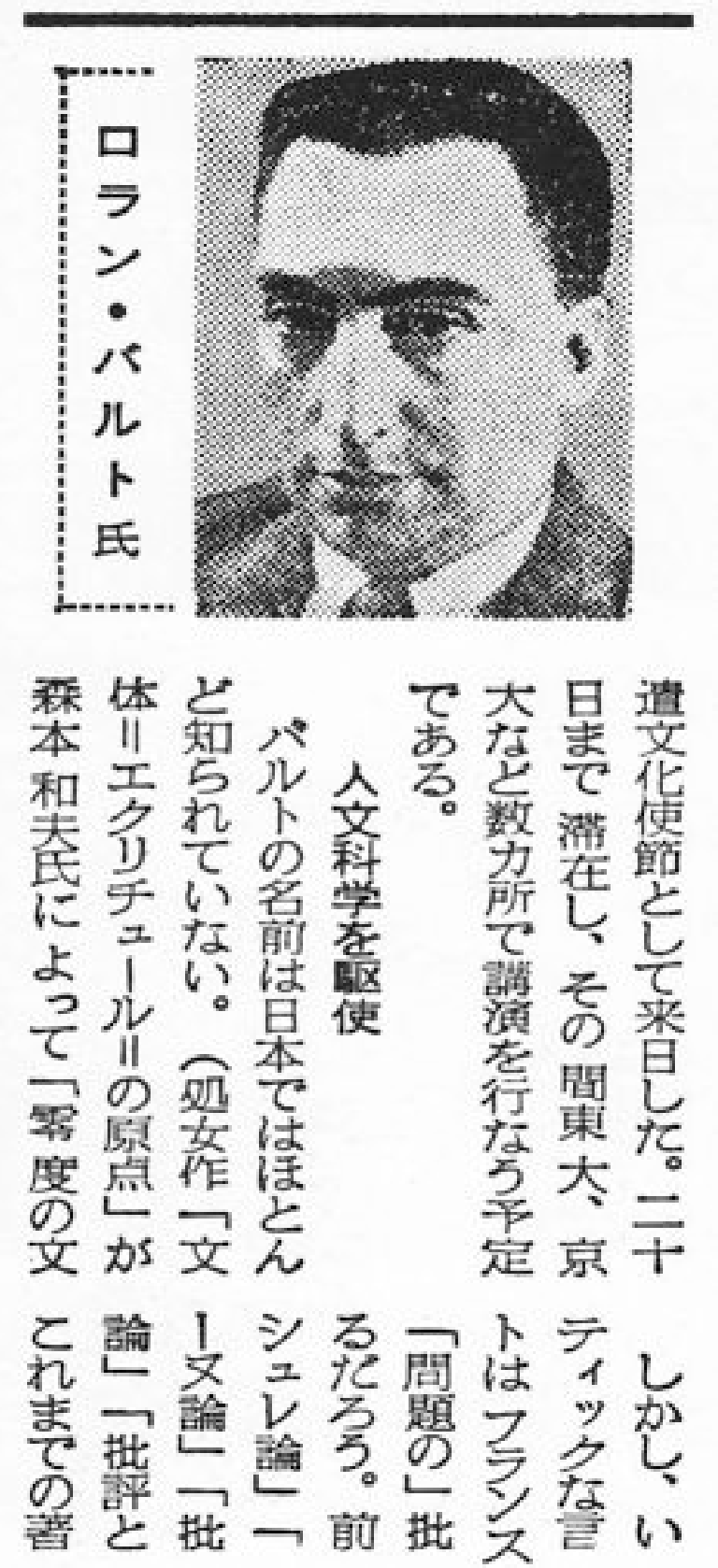
2. Para uma análise detalhada do lugar da fotografia na obra barthesiana, cf. a tese de Magali mythologies individuelles: mythologies individuelles. de Nadja à Sophio de Nadja à Sophie Calle", recentemente transformada em thro sob titulo Les mythologies individuelles: récit de soi et photographie au 20e siècle. Embora náo siga de perto a extensa análise da autora, valho-me aqui de informações e indicaçoes apresentadas por achtergael, em especial da relação que ela estabelece entre fragmento e fotografia na obra barthesiana.

3. BARTHES. O império dos signos texto e imagem que ressurgirá, sob outras formas, em textos posteriores do autor: ${ }^{2}$ Roland Barthes por Roland Barthes e $A$ câmara clara.

A empresa autobiográfica barthesiana é complexa, e não tenho a pretensão de fazer dela uma análise ampla ou de avaliar o tipo de inflexão que ela implica no conjunto da obra do autor francês. Ela aqui me interessa sobretudo pelo modo singular como conecta escrita autobiográfica e fotografia, num dispositivo híbrido, fragmentário, que coloca em questão não apenas a relação entre texto e imagem, entre escrit de si e imagem de si, mas também a própria prática do livro.

O império dos signos abre com uma espécie de advertência sobre a relação entre texto e imagem, que faz as vezes de projeto ou programa:

O texto não "comenta" as imagens. As imagens não "ilustram" o texto: cada uma foi, para mim, somente a origem de uma espécie de vacilação visual, análoga, talvez, àquela perda de sentido que o Zen chama de satori; texto e imagens, em seus entrelaçamentos, querem garantir a circulação, a troca destes significantes: o corpo, o rosto, a escrita, e nele ler o recuo dos signos. ${ }^{3}$

O tema da "perda de sentido" assume formas variadas na obra barthesiana - o sonho de um mundo "isento de sentido", o "significante sem significado", o satori, o "neutro". Talvez seja surpreendente que justamente Barthes, que nos ensinou a ver sentido em toda parte, que nos mostrou que nunca se escapa do sentido, apresente essa demanda de uma "isenção do sentido". Em Roland Barthes por Roland Barthes, o autor sustenta que não se trata de postular a existência de algo anterior ao sentido, mas de uma condição posterior, além do sentido - a "utopia" de um estado de isenção alcançado após o percurso de "todo o sentido". ${ }^{4}$ No texto introdutório de $O$ império dos signos, que acabo de citar, essa perda do sentido está relacionada com uma espécie de "vacilação" entre texto e imagem, que, em seus entrelaçamentos, garantem a "circulação" do significante.

Cinco anos depois de $O$ império dos signos, o autor lança Roland Barthes por Roland Barthes, escrito para atender a uma encomenda do fotógrafo Denis Roche, então responsável pela coleção "Microcosmos - Écrivains de toujours" das Éditions du Seuil (a mesma coleção para a qual Barthes havia contribuído com um volume sobre Michelet). Em 1980, será a vez de A câmara clara, um livro extremamente influente de teoria e crítica da fotografia, que incorpora também, no entanto, uma dimensão autobiográfica, e que se apresenta, igualmente, como uma montagem de texto e imagem.

Roland Barthes por Roland Barthes é uma espécie de autobiografia intelectual do autor; nas palavras de Pozuelo Yvancos,
EM TESE
BELO HORIZONTE
v. 21
N. 2
MAIO-AGO. 2015
MARQUES. A Fotografia do Jardim de Inverno: Barthes, fragmento, fotografia P. 11-28

4. BARTHES. Roland Barthes por Roland Barthes, p. 100-101. 
5. POZUELO YVANCOS. De la autobiografía, p. 214

6. BARTHES. Roland Barthes por Roland Barthes, p. 136.

7. BARTHES. Roland Barthes por Roland Barthes, p. 14.

8. Como se vê claramente em passagens como: "Eis-me aqui, eu próprio, como medida do 'saber' fotográfico. O que meu corpo sabe da fotografia?". BARTHES. A câmara clara, p. 20. Ou ainda: "Decidi entáo tomar como guia de minha nova analise a atração que eu sentia por certas fotos. BARTHES. A câmara clara, p. 35. A propria noção de punctum (aquilo que, na foto, me atrai ou me fere, $m e$ punge), em oposição à ideia de studium (campo de interesse cultural da foto), relaciona-se com a experiência singular do sujeito diante da imagem ("dar exemplos de punctum", diz Barthes, "É, BARTHES. A câmara clara, p. 69). "um testamento intelectual, uma declaração de seus princípios, de suas observações e de suas máscaras". ${ }^{5}$ Barthes faz aí, ao mesmo tempo, uma apresentação de suas ideias, de suas preocupações e de seu estilo e uma revisão crítica da própria obra (a determinada altura, o autor se refere ao livro como "o livro de minhas resistências a minhas próprias ideias"). ${ }^{6}$

O livro é dividido em duas partes. A primeira é composta por uma espécie de álbum de família, precedido de um breve texto de abertura. Nele, Barthes afirma ter escolhido as foto que o "sideram", sem que ele saiba a razão - um "imaginário de imagens" que abarca quase exclusivamente o período da infância e da juventude (voltarei a esse texto introdutório logo mais). Essa primeira parte tem cerca de 40 páginas de fotos entremeadas a pequenos fragmentos textuais, às vezes apenas uma legenda, às vezes apenas um título, às vezes um texto um pouco mais extenso, que identifica e comenta as fotografias, estabelece relações entre elas, mas, sobretudo, trata de indicar a relação/reação de Barthes a essas imagens (algo que em A câmara clara será alçado à condição de uma espécie de "método"). ${ }^{8}$ A disposição variada do texto em relação às imagens (acima, abaixo, ao lado das fotos), os jogos e associações entre as fotografias, o aproveitamento dos espaços em branco revelam uma atenção à montagem e à composição da página - o modelo do álbum fotográfico serve aqui à reconfiguração do relato autobiográfico.
A segunda parte do livro é composta por textos organizados em entradas alfabéticas (com títulos como "Adjetivo", "O escritor como fantasma", "Uma lembrança de infância", "Enxaquecas", "Projetos de livros", "Relação com a psicanálise”, etc.). Apesar da nítida divisão entre uma parte dedicada às fotografias e outra dedicada ao texto, a separação entre texto e imagem não é aqui absoluta, já que tanto na primeira parte há textos que acompanham as imagens, quanto na segunda há algumas poucas imagens entremeadas ao texto, sobretudo imagens da própria escrita (fichas, anotações, manuscritos) - aspecto da montagem, da disposição do texto e das imagens, que revela uma preocupação com a composição do livro, ${ }^{9}$ uma atenção ao livro como objeto material, sem dúvida já presente em $O$ império dos signos.

A eleição do fragmento não é novidade na obra barthesiana Como nota Pozuelo Yvancos, o fragmento teve na obra do autor francês importância constante, mas também crescente, como atestam seus três últimos livros - além do Roland Barthes por Roland Barthes, Fragmentos de um discurso amoroso e A câmara clara -, todos eles textos que adotam, em maior ou menor grau, uma forma fragmentária. No Roland Barthes por Roland Barthes e também em A câmara clara, talvez seja possível entender a opção pelo fragmento como uma espécie de contaminação do dispositivo fotográfico; o texto tende ao fragmento, à descontinuidade, como se, sob o influxo da
9. Em uma entrevista realizada em 1980, por ocasião do lançamento de $A$ câmara clara, e apenas um mês antes de sua morte, Barthes relações entre texto e imagem: “Há um trabalho de que eu gosto "Hă um trabalho de que eu gosto enormemente, é aquele que relação entre o texto e a imagem. Fiz isso multas vezes, e sempre com un prazer inenso. Adoro em meu livro sobre o Japão, meu pequeno livro o Japăo, em lui-même nas edições Seuil, uirme fazer isso pe tercira vez". (Barthes se refela terceira A câmara clara) ["ll y a un travail A cámara clara) ["lly y un travil que jaime énormément, c'est celui qui consiste à monter un Je l'ai fait plusieurs fois, et te lai fait plusieurs fois, et toujours avec un plaisir immense. Je l'ai fait dans mon livres. Je l'ai fait dans mon livre sur Barthes par lui-mêt petit livre Barthes par lui-meme au Seuil, et je viens donc de le faire une troisième fois"]. BARTHES. Sur la photographie, p. 79
EM TESE
BELO HORIZONTE
v. 21
N. 2
MAIO-AG0. 2015
MAROUES. A Fotografia do Jardim de Inverno: Barthes, fragmento, fotografia $\quad$ p. 11-28 
10. BARTHES. Roland Barthes por Roland Barthes, p. 83-84.

11. Barthes dedicou um grande interesse ao haicai, e esse interesse teve consequências em varias de suas formulações inclusive no que se refere à fotografia. Em $A$ preparação do romance, curso ministrado de 1978 e 1980 no College de France, 0 autor francês desenvolve a relaça entre haica e fotografia: "Minha proposta é que o haicai se aproxima muito foi'"'. BARTHES. A priaparacso roman. BARTHES. A preparação do romance 1, p. 148. O autor propó "uma forma breve". BARTHES. A preparma breve . BARTHES. A preparaçáo do romance l, $\mathrm{p}$. 152. Tambem em $A$ câmara clara a fotografia (ou, antes, "certas
fotografias") é aproximada do haicai: "Isso aproxima a fotografia haicai: "Isso aproxima a fotografias
(certas fotografias) do Haiku. (certas imagem fotográfica, sofresse uma espécie de mutação. Numa das entradas de Roland Barthes por Roland Barthes, fragmento e fotografia são elencados numa mesma lista de elementos unidos pelo "gosto da divisão": "Gosto pela divisão: as parcelas, as miniaturas, os contornos, as precisões brilhantes (tal é o efeito produzido pelo Haxixe, segundo Baudelaire), a vista dos campos, as janelas, o haicai, o traço, a escrita, o fragmento, a fotografia, o palco à italiana [...]”. ${ }^{10}$ A foto é também uma forma breve, um fragmento - ela mostra uma porção do espaço num instante do tempo -, captura sempre parcial do mundo.

O gosto pelo fragmento é ainda tematizado em Roland Barthe por Roland Barthes nas entradas "O círculo dos fragmentos", "O fragmento como ilusão" e "Do fragmento ao diário". Vou resistir à tentação de reproduzir integralmente essas passagens (de resto, um desejo que se repete ao lidar com qualquer texto de Barthes, sempre tão citável), em que o autor afirma que "escrever por fragmentos" é procedimento presente desde seu primeiro texto e relaciona tal procedimento ao seu gosto pelo pormenor e pela escrita dos começos (associados à inabilidade para a "composição" e ao desapreço pelo fim), ao haicai, ${ }^{11}$ ao verso, à música e, por fim, ao diário. Limito-me a citar os dois primeiros parágrafos de "O círculo dos fragmentos":

Escrever por fragmentos: os fragmentos são então pedras sobre o contorno do círculo: espalho-me à roda: todo o meu pequeno universo em migalhas; no centro, o quê?
Seu primeiro texto ou quase (1942) é feito de fragmentos; essa escolha justificava-se então à maneira de Gide "porque a incoerência é preferível à ordem que deforma”. Desde então, de fato, ele não cessou de praticar a escritura curta: quadrinhos das Mitologias e de $O$ império dos signos, artigos e prefácios dos Ensaios críticos, lexias de $S / Z$, parágrafos intitulados de Michelet, fragmentos de Sade II e de O prazer do texto. ${ }^{12}$

Essa passagem me interessa por outros motivos além de tratar da eleição do fragmento como forma. Em primeiro lugar, ela associa a fragmentação do texto a uma certa dispersão do sujeito ("espalho-me à roda"), dispersão a que se fará referência em outros momentos do livro. Em segundo lugar, ela de certa forma encena uma oscilação ou divisão enunciativa que ocorrerá ao longo de todo o livro: Barthes começa o texto em primeira pessoa, para logo em seguida passar à terceira. Está aí implicado o próprio gesto autobiográfico, que será colocado em questão ao longo de todo o texto. Não por acaso, muitos autores consideraram o Roland Barthes por Roland Barthes como uma espécie de "antiautobiografia", ${ }^{13}$ ou de autobiografia irônica, biografia que parece criada, antes, para desconstruir e problematizar o gênero.

A advertência que abre o livro (e que se repete no fragmento intitulado "O livro do Eu") - "Tudo isto deve ser considerado como dito por uma personagem de romance"14 em letra manuscrita, é um gesto decisivo de afastamento de
11. > > > Pois a notação de um haiku também é indesenvolvível: tudo está dado, sem provocar vontade ou mesmo a possibilidade de uma expansão retórica. Nos dois casos, poderíamos, deveríamos falar de uma imobilidade viva: ligada a um detalhe (a um detonador), uma explosão produz uma estrelinha no vidro do texto ou da foto: nem o Haiku nem a Foto fazem 'sonhar'". BARTHES. A câmara clara, p. 78. Para uma análise da relação de Barthes com o haicai cf. NACHTERGAEL. Esthétique des mythologies individuelles: Le dispositif photographique de Nadja à Sophie Calle, em especial p. 259-264.

12. BARTHES. Roland Barthes por Roland Barthes, p. 108

3. Cf. POZUELO YVANCOS. De I autobiografía, p. 225

14. BARTHES. Roland Barthes por Roland Barthes, p. 11.
EM TESE
BELO HORIZONTE
v. 21
N. 2
MA1-AGO. 2015
MARQUES. A Fotografia do Jardim de Inverno: Barthes, fragmento, fotografia $\quad$ P. 11-28 
15. BARTHES. Roland Barthes por Roland Barthes, p. 160.

16. Num esclarecedor ensaio sobre o autor francês, Susan Sontag apresenta nos seguintes termos a empresa autobiográfica barthesiana: “Quando

autobiográfica a obra inclui

invariavelmente confissões de

relutância a falar na primeira

pessoa. Uma das convenções

de Roland Barthes é referir-se o

autobiógrafo a si mesmo às vezes

como 'eu' e outras vezes como

'ele'. Tudo isso, declara Barthes

na primeira página do seu livro

sobre si mesmo, 'deve ser

considerado como algo dito por

um personagem num romance.

$>>>$

17. BARTHES. Roland Barthes por Roland Barthes, p. 136-137. qualquer ilusão de coincidência entre um "eu" textual (que aqui se apresenta frequentemente como "ele") e um "eu", digamos, da experiência. A partir daí, o texto não faz mais do que lançar suspeitas a respeito do sujeito da autobiografia com a oscilação entre a primeira e a terceira pessoa, a insistência no problema da dispersão do sujeito ("não sou contraditório, sou disperso"), ${ }^{15}$ e mesmo a tematização explícita do autobiográfico como problema. ${ }^{16}$

Em "O livro do eu", Barthes retoma a frase de abertur do livro, lançando-o para o domínio do romanesco ("[...] A substância deste livro, enfim, é pois totalmente romanesca") e apresentando o sujeito que fala como máscara (sem que haja no entanto "ninguém por detrás"). ${ }^{17}$

Em "Lucidez", o problema do autobiográfico é tratado por outro viés, o do tempo, ou, antes, o do desencaixe de tempos da autobiografia, que sempre se escreve a partir do presente:

Este livro não é um livro de "confissões”; não porque ele seja insincero, mas porque temos hoje um saber diferente do de ontem; esse saber pode ser assim resumido: o que escrevo de mim nunca é a última palavra: quanto mais sou "sincero", mais sou interpretável, sob o olhar de instâncias diferentes das dos antigos autores, que acreditavam dever submeter-se a uma única lei: a autenticidade. Essas instâncias são a História, a Ideologia, o Inconsciente. Abertos (e como poderia ser de outro modo?) para esses diferentes futuros, meus textos se desencaixam, nenhum vem coroar o outro; este aqui não é nada mais do que um texto $a$ mais, o último da série, não o último do sentido: texto sobre texto, nada é jamais esclarecido.

Que direito tem o meu presente de falar de meu passado? Meu presente tem algum poder sobre meu passado? Que "graça" me teria iluminado? Somente a do tempo que passa, ou de uma boa causa encontrada em meu caminho ${ }^{18}$

A autobiografia, então, não é uma questão de "sinceridade" ou de "autenticidade", mas de um inevitável desajuste temporal. O texto está inevitavelmente ancorado no presente; é a partir daí que se fala (mas quem o autoriza?) sobre o passado (um problema narrativo, em suma). Um texto nunca é definitivo, nunca tem a "última palavra"; ele sempre entra (mais um) no jogo de outros textos (é o "último da série, não o último do sentido").

Por fim, em "Quanto a mim, eu", Barthes começa por identificar o par subjetividade/objetividade como um "velho paradigma"; hoje, a subjetividade - "desconstruída, desunida, deportada, sem ancoragem" - "pode voltar num outro trecho da espiral". ${ }^{19}$ Barthes trata então da questão dos pronomes pessoais, aspecto central do discurso autobiográfico:

Pronomes ditos pessoais: tudo se joga aqui, estou fechado para sempre na liça pronominal: o "eu" mobiliza o imagi-
16. >>> Sob a metacategoria da atuação, não só a fronteira entre autobiografia e ficção é esmaecida como também a fronteira entre ensaio e ficção. 'Que este ensaio admita ser quase um romance', diz ele em Roland Barthes. A escrita registra novas formas de ênfase dramática, de um tipo autorreferente: a escrita se torna o registro de compulsões e de resistências a escrever. (No prolongamento dessa concepção, a escrita em si torna-se o tema do escritor)". SONTAG. A escrita em si mesma: sobre Roland Barthes, p. 97

18. BARTHES. Roland Barthes por Roland Barthes, p. 137.

19. BARTHES. Roland Barthes por Roland Barthes, p. 185. 
20. BARTHES. Roland Barthes por Roland Barthes, p. 186. nário, o "você" e o "ele" a paranoia. Mas também, fugitivamente, conforme o leitor, tudo, como os reflexos de um chamalote, pode revirar-se: em "quanto a mim, eu", o "eu" pode não ser o mim, que ele quebra de um modo carnavalesco; posso me chamar de "você", como Sade o fazia, para destacar em mim o operário, o fabricante, o produtor de escritura, do sujeito da obra (o Autor); por outro lado, não falar de si pode querer dizer: eu sou Aquele que não fala dele, e falar de si dizendo "ele", pode querer dizer: falo de mim como se estivesse um pouco morto, preso numa leve bruma de ênfase paranoica, ou ainda: falo de mim como o autor brechtiano que deve distanciar sua personagem: mostrá-lo, não encarná-lo, dar à sua dicção uma espécie de piparote, cujo efeito é descolar o pronome de seu nome, a imagem de seu suporte, o imaginário de seu espelho (Brecht recomendava ao ator que pensasse todo o seu papel na terceira pessoa). ${ }^{20}$

Falar de si como um outro, falar como um ator (brechtiano), ou, ainda, "como se estivesse um pouco morto" - eis, ao que parece, a condição do autobiográfico. Do mesmo modo que, como diz Barthes, na expressão "Quanto a mim, eu", "eu" e "mim" podem não coincidir, a duplicação do nome próprio do autor no título de Roland Barthes por Roland Barthes pode ser lida como uma cisão entre sujeito que escreve e sujeito da escrita, entre "eu" e "mim". Assim (ao contrário talvez do que a formulação de Lejeune, com sua ênfase na coincidência entre autor, narrador e personagem, dá a entender), o gesto autobiográfico não implicaria coincidência, mas duplicação, cisão, quebra, diferença de si em relação a si mesmo.

Um dispositivo que mostra de forma pungente essa diferença de si para si é, sem dúvida, a fotografia. Em $O$ ato fotográfico, Dubois se refere a esse "[...] irresistível sentimento de estranheza que invade qualquer indivíduo da primeira vez que olha para sua imagem fotográfica: 'eu' começa sempre por ser um outro; eu (me) vejo, portanto não sou (aquele lá)". ${ }^{21}$ Essa estranheza aparece logo na abertura do Roland Barthes por Roland Barthes, na forma de uma "inquietante familiaridade" em relação às fotografias da própria juventude. "São somente as imagens de minha juventude que me fascinam”, diz Barthes. Esse fascínio, que o autor afirma não saber explicar, é apresentado como uma "sideração":

Quando a meditação (a sideração) constitui a imagem como ser destacado, quando ela a transforma em objeto de um gozo imediato, não tem mais nada a ver com a reflexão, por sonhadora que fosse, de uma identidade; ela se atormenta e se encanta com uma visão que não é de modo algum morfológica (eu nunca me pareço comigo), mas antes orgânica. Abarcando todo o campo parental, a imageria age como um médium e me põe em relação com o "isto" de meu corpo; ela
EM TESE
BELO HORIZONTE
v. 21
N. 2
MAIO-AGO. 2015
MAROUES. A Fotografia do Jardim de Inverno: Barthes, fragmento, fotografia P. 11-28 
22. BARTHES. Roland Barthes por Roland Barthes, p. 13-14. suscita em mim uma espécie de sonho obtuso, cujas unidades são dentes, cabelos, um nariz, uma magreza, pernas com meias compridas, que não me pertencem, sem no entanto pertencer a mais ninguém; eis-me então em estado de inquietante familiaridade: vejo a fissura do sujeito (exatamente aquilo de que ele não pode dizer nada). Disso decorre que a fotografia de juventude é, ao mesmo tempo, muito indiscreta (é meu corpo de baixo que ela dá a ler) e muito discreta (não é de "mim" que ela fala). ${ }^{22}$

O texto é intrincado, e não vou tentar fornecer dele uma análise exaustiva. Apenas me interessa reter algumas questões, relativas à compreensão da imagem fotográfica, e em particular da imagem fotográfica de si. Em primeiro lugar diz Barthes, o que fascina não é a "reflexão [...] de uma identidade”. Também não se trata de uma questão de semelhança ("eu nunca me pareço comigo"). Essa "imageria", "abarcando todo o campo parental", afirma Barthes, "me põe em relação com o 'isto' do meu corpo". A menção, nesse ponto específico, ao "campo parental" parece referir-se à identificação de algo como uma história (ou uma "pré-história") do corpo a detecção de alguma coisa de si no corpo de um ancestral, permitida pela fotografia. O “'isto' de meu corpo" antecipa a percepção da dimensão de designação da imagem fotográfica que encontrará depois formulação no "isto foi”, em A câmara clara. O que mais me interessa nesse trecho, no entanto, é a percepção de uma diferença ou intervalo em relação a si mesmo (as pernas com meias compridas com que me vejo na fotografia não me pertencem, sem pertencer a mais ninguém; a fotografia de juventude dá a ver o meu corpo, mas não é de "mim" que ela fala). "Vejo", diz Barthes (e a escolha do campo lexical da visão aqui não é obviamente casual), "a fissura do sujeito”. A fotografia, portanto, não expõe a coincidência, mas, antes, a fissura do sujeito que marca o gesto autobiográfico.

As fotografias apresentadas na primeira parte do Roland Barthes por Roland Barthes mostram, diz o autor, "figurações de uma pré-história do corpo". ${ }^{23}$ Por esse motivo, o "imaginário de imagens" será detido com a entrada na vida adulta, a partir da qual um outro imaginário se instala: o do texto, o da "escritura". A infância e a juventude não são tratadas no texto; aparecem apenas como corpo, na forma de fotografias (às quais, é preciso lembrar, se apõem no entanto alguns breves excertos textuais). Com a entrada na "vida produtiva", que marca o advento do texto, da escrita, o sujeito despoja-se de si mesmo, se dispersa (na segunda parte do Roland Barthes por Roland Barthes, encontramos o autor convertido em uma série de entradas enciclopédicas, um conjunto textos que versam sobre seus pensamentos, gostos ou ideias, um sujeito tornado, como demonstram as únicas imagens autorizadas a figurar nessa parte do livro, ficha, fichário).
23. BARTHES. Roland Barthes por Roland Barthes, p. 14.
EM TESE
BELO HORIZONTE
v. 21
N. 2
MAIO-AGO. 2015
MAROUES. A Fotografia do Jardim de Inverno: Barthes, fragmento, fotografia $\quad$ p. 11-28 


\section{mo BatThES}

- Fichas
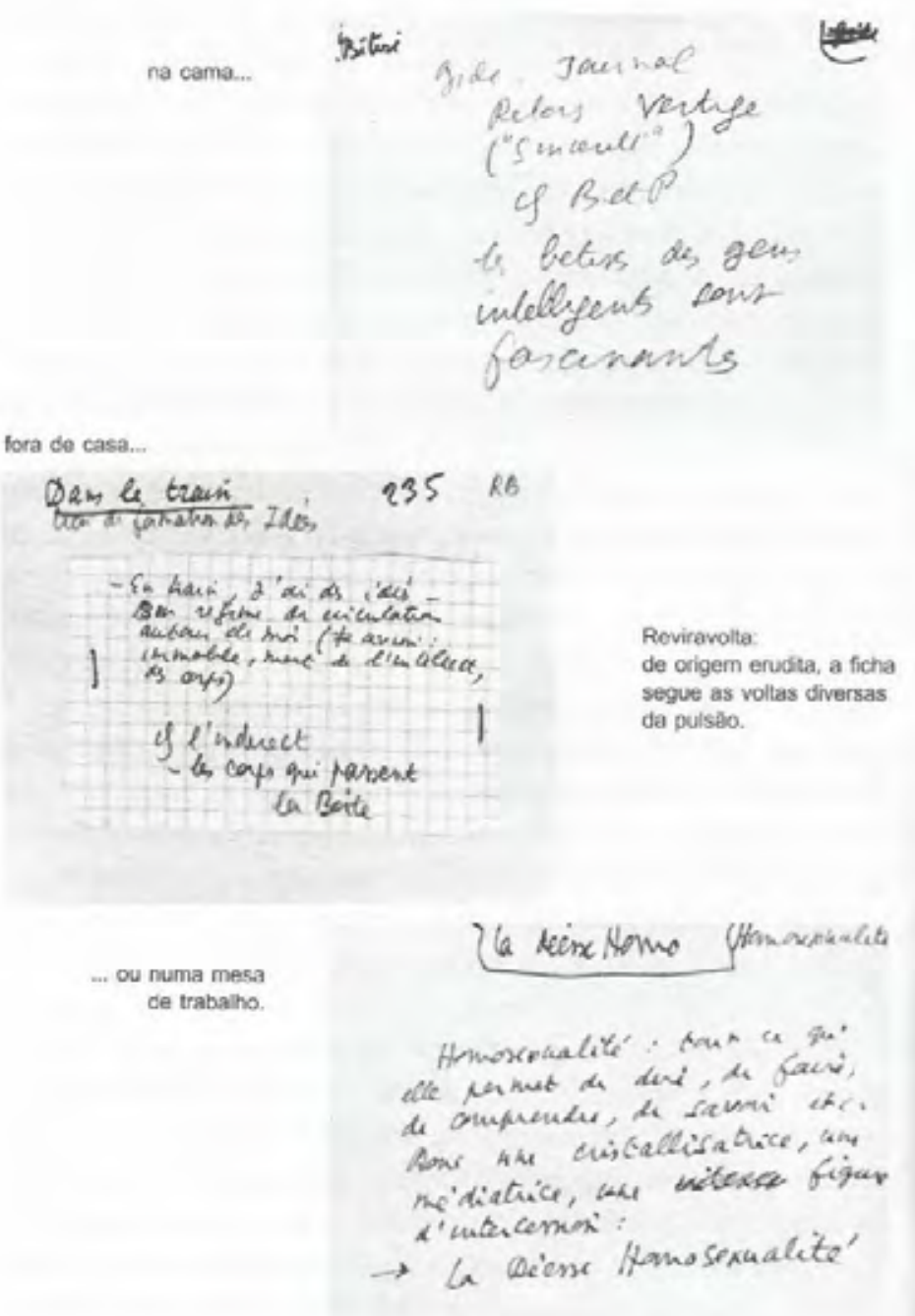

Mais adiante, no texto que acompanha duas fotografias do autor (uma de 1942, outra de 1970), Barthes escreve:

Mas eu nunca me pareci com isto!

- Como é que você sabe? Que é este "você" com o qual você se pareceria ou não? Onde tomá-lo? Segundo que padrão morfológico ou expressivo? Onde está seu corpo de verdade?

Você é o único que só pode se ver em imagem, você nunca vê seus olhos, a não ser abobalhados pelo olhar que eles pousam sobre o espelho ou sobre a objetiva (interessar-me-ia somente ver meus olhos quando eles te olham): mesmo e sobretudo quanto a seu corpo, você está condenado ao imaginário. ${ }^{24}$

A impossibilidade (comum a todos nós) de ver a si mesmo, a não ser no espelho ou na fotografia, essa "condenação" ao "imaginário" mesmo (e sobretudo) quanto ao próprio corpo ("você é o único que só pode se ver em imagem”), que bloqueia a percepção da semelhança (não posso saber com o que me pareço), faz do dispositivo fotográfico o lugar de uma "dissociação astuciosa da consciência de identidade", como se lê em A câmara clara: "Eu queria uma história dos Olhares. Pois a Fotografia é o advento de mim mesmo como outro: uma dissociação astuciosa da consciência de identidade". ${ }^{25}$ A "loucura profunda da fotografia" ${ }^{26}$ está relacionada com a experiência desse momento em que não sou sujeito nem objeto, "mas antes um sujeito
24. BARTHES. Roland Barthes por Roland Barthes, p. 48.

25. BARTHES. A câmara clara, p. 25.

26. Barthes nota que "foi antes da Fotografia que os homens mais falaram da visão do

duplo. Costuma-se aproximar a ela foi, durante séculos, um ela foi, durante seculos, um grande tema mitico. Hoje, porem è como se recalcássemos a loucura profunda da fotografia: ela lembra sua herança mítica apenas por esse ligeiro mal-estar que me toma quando "me' olho ên um papel. BARTHES. A 
27. BARTHES. A câmara clara, p. 27.

28. BARTHES. Sade, Fourier, Loyola, p. 12.

29. Reproduzo a seguir o período completo: “Porque, se é necessário que, por uma retórica arrevesada, haja no Texto, um sujeito para se o sujeito, sujeito é disperso, um pouco sujelto e disperso, um pouco como as cinzas que se atiram da vrna a da a mo fortes, fechas in destes, fechados, instituidores de de lembran-se-lam ó cavacos de lembrança, a erosăo que só veixa da vida passada alguns ví mos): se eu fosse escritor, já morto, como gostaria que a minha vida se reduzisse, pelos cuidados de um biógrafo amigo e desenvolto, a alguns pormenores, a alguns gostos, a algumas inflexões, digamos: >>> que se sente tornar-se objeto: vivo então uma microexperiência da morte (do parêntese): torno-me verdadeiramente espectro". 27

Assim, Roland Barthes por Roland Barthes ao mesmo tempo tematiza e realiza uma reconfiguração da escrita autobiográfica que passa pela eleição da forma do fragmento e pela fotografia, e ainda pela relação de ambas com a noção de um sujeito não apenas cindido, mas desunido, disperso, tornado outro, duplo de si mesmo. Ambos, fragmento e fotografia, são dispositivos de um pensamento do descontínuo, da interrupção, da parada, que implica uma resistência à narratividade (é a narrativa que cria a ilusão de coerência do sujeito). Essa concepção fragmentária, descontínua, do biográfico aparece bem antes na obra barthesiana, com a noção de biografema, introduzida pelo autor no prefácio de seu livro Sade, Fourier, Loyola:

[...] se eu fosse um escritor, já morto, como gostaria que a minha vida se reduzisse, pelos cuidados de um biógrafo amigo e desenvolto, a alguns pormenores, a alguns gostos, a algumas inflexões, digamos: "biografemas", cuja distinção e mobilidade poderiam viajar fora de qualquer destino e vir tocar, à maneira dos átomos epicurianos, algum corpo futuro, prometido à mesma dispersão; uma vida furada, em suma $[\ldots] .^{28}$
Encontramos aí formulada a ideia de uma biografia que se detém em certos traços, detalhes, pormenores, aos quais, pelos cuidados de um biógrafo, se reduz o fluxo de uma vida - que, nesse gesto, se esgarça, torna-se "furada". Partícula mínima da biografia, "à maneira dos átomos epicurianos", o biografema se caracteriza pela "mobilidade", e portanto pela disponibilidade para tocar "algum corpo futuro", pela abertura para o outro (para a leitura).

Essa passagem é muito citada, geralmente - como, aliás, eu fiz - omitindo-se a primeira e a última parte desse longo e complexo período ${ }^{29}$ no qual se assiste ao nascimento da ideia de "biografema". Na primeira parte do período, Barthes diz que, se, no texto, destruidor de todo sujeito, é preciso ainda assim haver um "sujeito para se amar", esse sujeito é disperso, como as cinzas atiradas ao vento após a morte. $\mathrm{Na}$ parte final, a "vida furada" é comparada àquela que Proust soube escrever em sua obra, mas também - analogia que aqui nos interessa de perto - a um "filme à moda antiga, de que está ausente toda palavra [aqui, o termo "parole" seria mais precisamente traduzido por "fala" ou "diálogo"] e cuja vaga de imagens [...] é entrecortada, à moda de soluços salutares, pelo negro apenas escrito do intertítulo, a irrupção desenvolta de outro significante [...]".$^{30}$ No exemplo de Barthes, é a escrita que vem interromper, entrecortar, furar “à moda de soluços salutares”, o fluxo das imagens. Podemos
29. >>> 'biografemas', cuja distinção e mobilidade poderiam viajar fora de qualquer destino e vir tocar, à maneira dos átomos epicurianos, algum corpo futuro, prometido à mesma dispersão; uma via furada, em suma, como Proust soube escrever a sua na sua obra, ou então um filme à moda antiga, de que está ausente toda palavra e cuja vaga de imagens (esse flumen orationis em que talvez consista o 'lado porco' da escritura) é entrecortada, à moda de soluços salutares, pelo negro apenas escrito do intertítulo, a irrupção desenvolta de outro significante: o regalo branco de Sade, os vasos de flores de Fourier, os olhos espanhóis de Inácio". BARTHES. Sade, Fourier, Loyola, p. 12.

30. BARTHES. Sade, Fourier, Loyola p. 12 
pensar que a irrupção de um meio significante por outro, o corte que vem interromper o fluxo, funciona ao inverso nos textos barthesianos que incorporam imagens fotográficas: neles, é a imagem que vem "furar" o texto, fragmentá-lo pela irrupção de um outro meio significante, ele mesmo um fragmento. Ou, ainda, podemos pensar que o Roland Barthes por Roland Barthes - tanto a primeira parte, com suas cadeias de imagens entrecortadas por legendas e comentários, como os intertítulos de um filme mudo, quanto a segunda, com suas entradas/fragmentos - realiza o propósito de "redução" da vida a certos traços e pormenores biográficos, Barthes assumindo assim ele mesmo o papel do próprio biógrafo "amigo e desenvolto".

Mais tarde, em A câmara clara, o autor estabelece uma comparação explícita entre fotografia e biografema, ao afirmar "gosto de certos traços biográficos que, na vida de um escritor, me encantam tanto quanto certas fotografias; chamei esses traços de "biografemas"; a Fotografia tem com a História a mesma relação que o biografema tem com a biografia". ${ }^{31}$ Fragmento da história, como o biografema é fragmento de uma biografia, a fotografia dá a ver, sempre, elementos parciais, subtraídos ao fluxo da vida e ao contínuo do espaço, detalhes, pormenores.

$$
* * *
$$

A câmara clara é uma reflexão sobre a fotografia, uma tentativa de estabelecer o traço distintivo da imagem fotográfica a partir de uma atenção às reações do próprio autor em relação às imagens, ou ainda, como sugere o título de um ensaio de Geoffrey Batchen, "uma outra pequena história da fotografia". ${ }^{32}$ Mas é também um livro que articula texto e imagem de forma intrincada, uma montagem de texto e fotografia que inclui numerosas reproduções fotográficas que são comentadas, legendadas, analisadas, colocadas em relação -, para contar uma história que é, afinal, uma história de luto.

Barthes está em busca do que distingue a fotografia na comunidade das imagens, e encontra como resposta o seu caráter indicial, a relação material que a foto mantém com seu objeto; essa relação, Barthes a descreve de várias formas ao longo do livro, referindo-se à "teimosia do Referente em estar sempre presente"; ${ }^{33}$ à "aderência singular" ${ }^{44}$ do referente; à foto como "literalmente uma emanação do referente". ${ }^{35}$ É isso o que explica "essa coisa um pouco terrível que há em toda fotografia: o retorno do morto". ${ }^{36}$

Afirmando tomar como guia sua própria reação a determinadas fotografias, Barthes formula a divisão entre dois elementos que fundariam sua atração por certas fotos: o studium e o punctum. Enquanto o studium tem relação com o "saber", com a "cultura", com a "informação", com o vasto
32. BATCHEN. Uma outra pequena história da fotografia. Batchen faz air referencia, obvianente, "Pequena história da fomin publicado em 1931, potogrifa"، publicado em 1931, portanto quase cinquenta an câmara clara.

33. BARTHES. $A$ câmara clara, p. 15-16.

34. BARTHES. A câmara clara, p. 16 35. BARTHES. A câmara clara, p. 121

36. BARTHES. A câmara clara, p. 20 
37. BARTHES. $A$ câmara clara, p. 85.

38. NACHTERGAEL. Esthétique des mythologies individuelles: Le dispositif photographique de
Nadja à Sophie Calle, p. 330.

39. BARTHES. A câmara clara, p. 11. “Un jour, il y a bien longtemps $\left.[\ldots]^{\prime \prime}\right]$

40. BARTHES. A câmara clara, p. 20. campo dos "interesses" (a foto como "testemunho político", "quadro histórico"...), o punctum é uma espécie de choque de reconhecimento, resposta única e pessoal ao detalhe fotográfico que ao mesmo tempo atrai e repele. Barthes também define o punctum como "suplemento": "é o que acrescento à foto e que todavia já está nela". ${ }^{37} \mathrm{O}$ punctum interrompe ou escande a leitura contextual, cultural, que Barthes chama de studium.

A câmara clara não inclui apenas reflexões sobre a fotografia, mas também um número considerável de fotos. Como uma espécie de "curador", Barthes seleciona, identifica, legenda e comenta 25 fotografias, de épocas diferentes - estão aí "a primeira foto" ("A mesa posta" de Niépce), a foto da mãe (ou esposa) de Nadar, fotografias de André Kertész, de Sader, de Mapplethorpe... É a partir delas (com elas) que Barthes constrói seu livro.

O livro é dividido em duas partes, compostas por fragmentos textuais numerados (48 no total). A primeira se apresenta como um ensaio (mesmo que, como nota Nachtergael, ${ }^{38}$ ela comece como um conto - "Um dia, há muito tempo..."). ${ }^{39}$ A segunda parte também se inicia à maneira de um conto, $\mathrm{e}$ é nela que o relato assume inflexão mais claramente pessoal, propriamente autobiográfica, que no entanto já se deixava entrever no recurso à primeira pessoa e na decisão de tomar a si próprio como "medida do 'saber' fotográfico". ${ }^{40}$

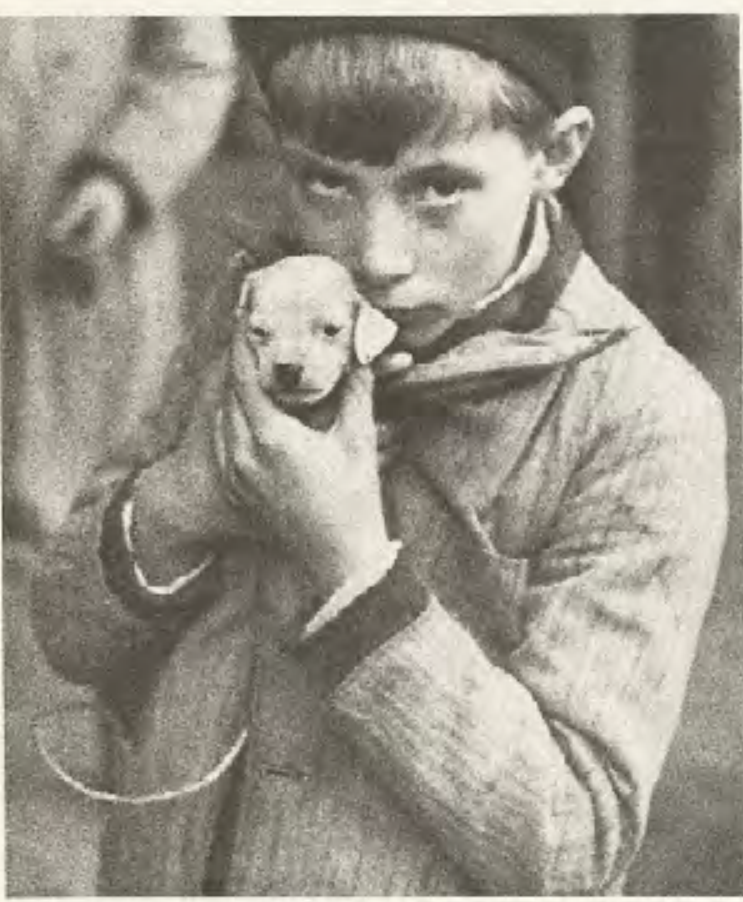

"Ele não olba nada;

ele retém para dentro

seu amor e seu medo:

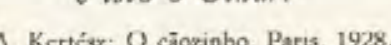


Ora, numa noite de novembro, pouco tempo depois da morte de minha mãe, organizei as fotos. Eu não contava "reencontrá-la", não esperava nada dessas "fotografias de um ser, diante das quais nos lembramos menos bem dele do que nos contentamos em pensar nele" (Proust). Eu sabia que, por essa fatalidade que é um dos traços mais atrozes do luto, eu consultaria imagens em vão, não poderia nunca mais lembrar-me de seus traços (convocá-los, inteiros, a mim). [...] Além do mais, essas fotos, se excetuarmos a que eu tinha publicado na qual se vê minha mãe, jovem, a caminhar por uma praia das Landes [Barthes se refere à primeira foto reproduzida no Roland Barthes por Roland Barthes] e na qual eu "reencontrava" seu andar, sua saúde, sua irradiação - mas não sua face, muito distante -, essas fotos que eu tinha dela, eu não podia sequer dizer que gostava delas: não me punha a contemplá-las, não mergulhava nelas. Eu as percorria, mas nenhuma me parecia verdadeiramente "boa": nem desempenho fotográfico, nem ressurreição viva da face amada. Se um dia viesse a mostrá-las a amigos, teria dúvidas de que elas lhes falassem. ${ }^{41}$

O livro assume então a forma de uma busca pela imagem materna (uma aventura), aquela que permitiria um "reencontro" com o ser amado e recentemente perdido (busca a que não falta certo suspense: "será que eu a reconheceria?") 42 : "Sozinho no apartamento em que ela há pouco tinha morrido, eu ia assim olhando sob a lâmpada, uma a uma, essas fotos de minha mãe, pouco a pouco remontando com ela o tempo, procurando a verdade da face que eu tinha amado. E descobri”. ${ }^{43}$

Curiosamente, é só numa fotografia da mãe aos cinco anos de idade que Barthes vai encontrar aquilo que procura. $\mathrm{O}$ desejo de reconhecimento é, assim, estranhamente satisfeito por uma imagem que o autor não teria como reconhecer. Ainda mais curioso, num livro em que há tantas reproduções fotográficas, essa fotografia não é reproduzida, mas apenas descrita. ${ }^{44} \mathrm{~A}$ fotografia central de $A$ câmara clara é, portanto, uma imagem ausente. Barthes não nos mostra a foto de sua mãe quando criança porque não poderíamos vê-la como ele a vê. Para nós, leitores, como afirma Hirsh,${ }^{45}$ excluídos da dinâmica da troca de olhares instaurada pela fotografia familiar, a "Fotografia do Jardim de Inverno" - aquela em que Barthes enfim reencontrava sua mãe "tal que em si mesma" - seria apenas outra fotografia de família genérica de muito tempo atrás. Como acrescenta Barthes, num parêntese em que se dirige aos leitores:

(Não posso mostrar a Foto do Jardim de Inverno. Ela existe apenas para mim. Para vocês, não seria nada além de uma foto indiferente, uma das mil manifestações do "qualquer"; ela não pode em nada constituir o objeto visível de uma ciência; não pode fundar uma objetividade, no sentido positivo do termo; quando muito interessaria ao studium de vocês;
43. BARTHES. A câmara clara, p. 101.

44. "A fotografia era muito antiga. Cartonada, os cantos machucados de um sepia empalidecido, mal deixava ver duas crianças de pe, formando grupo, na extremidade de uma pequena ponte de madeira em um Jardim de Inverno com teto de vidro. Minha mãe tinha na ocasião cinco anos (1898), seu irmão tinha sete. Ele apoiava as costas na balaustrada da ponte, sobre a qual estendera o braço; ela, mais distante, menor, mantinha-se de frente; sentia-se que o fotógrafo Ihe havia dito: 'Um pouco para frente, para que a gente possa te ver'; ela unira as mãos, uma segurando a outra por um dedo, como com frequência fazem as crianças, num gesto desajeitado. O irmão e a irmã, unidos entre si, eu o sabia, pela desunião dos pais, que se divorciariam pouco tempo depois, tinham posado lado a lado, sozinhos, no espaço aberto entre as folhagens e palmas da estufa (tratava-se da casa em que minha mãe tinha nascido, em Chennevières-sur-Marne)". BARTHES. A câmara clara, p. 101102.

45. HIRSH. Family frames, p. 2.

46. BARTHES. A câmara clara, p. 107. 
época, roupas, fotogenia; mas nela, para vocês, não há nenhuma ferida). ${ }^{47}$

É a partir daí que Barthes formula o "noema" da fotografia - "Isso-foi', ou ainda: o Intratável”. ${ }^{48}$ A foto como emanação do referente, de um corpo real, encontra ainda nessa parte do livro uma formulação de modo algum casual: "uma espécie de vinculo umbilical", diz Barthes, "liga a meu olhar o corpo da coisa fotografada" ${ }^{49}$ (grifo meu). É também a partir daí que ele chega a uma outra definição de punctum: não só o detalhe, mas o próprio tempo. Isso vai ser e isso foi: "Diante da foto de minha mãe criança, eu me digo: ela vai morrer: estremeço, tal como o psicótico de Winnicott, por uma catástrofe que já ocorreu. Que o sujeito já esteja morto ou não, qualquer fotografia é essa catástrofe”.$^{50}$

A câmara clara é, assim, um livro de teoria atravessado pela fotografia e pela autobiografia; é também resultado de uma prática do livro que incorpora a fotografia como componente pictural, mas também argumentativo; um romance do luto e uma aventura de busca (por uma imagem - "uma imagem que fosse a um só tempo justiça e justeza justo uma imagem, mas uma imagem justa"); ${ }^{51}$ meditação sobre o tempo e a morte tal como se mostram pela fotografia; autobiografia em imagens à qual falta no entanto a única foto que a justifica e mobiliza.

\section{EM TORNO DE BARTHES: A IMAGEM FANTASMA}

Algo parece ligar a prática fotográfica e a escrita de si. Esse laço pode ser investigado não apenas no campo da literatura, mas se faz especialmente presente nas artes visuais pelo menos desde a década de 1970 .

Os surrealistas já se apropriavam da fotografia como material; explorada em seu caráter de objeto, e não mais, apenas, de mídia, a fotografia torna-se, na colagem dadaísta e surrealista, um material entre outros. Com o desenvolvimento dos meios de reprodutibilidade técnica, que permitiram sua difusão na imprensa e na publicidade, além do amplo acesso aos aparelhos fotográficos e da conversão da prática fotográfica em atividade de massa, a fotografia alcançou uma quase ubiquidade. A imagem fotográfica acaba, assim, por se tornar material disponível para outros usos e contextos, invadindo o campo artístico por meio de diferentes práticas de produção e apropriação (a colagem, o reemprego, a manipulação, a instalação, o readymade).

Muitos artistas têm-se voltado para a apropriação de fotografias de amadores ou de acervos fotográficos públicos e privados. É o caso, para citar apenas alguns exemplos, do Atlas de Gerhard Richter; da apropriação de fotografias de família em Christian Boltanski; das operações sobre o arquivo em Rosângela Rennó. Em casos recentes, é a própria fotografia amadora que faz entrada no museu pelo trabalho
EM TESE
BELO HORIZONTE
v. 21
N. 2
MAIO-AGO. 2015
MARQUES. A Fotografia do Jardim de Inverno: Barthes, fragmento, fotografia P. 11-28 
de curadoria. Essa operação coloca sem dúvida inúmeras questões para os críticos de arte contemporânea ou mesmo para uma antropologia das imagens fotográficas, que não serão, no entanto, exploradas aqui. Vários autores, entre os quais Susan Sontag, Philippe Dubois e Rosalind Krauss, discutiram não apenas a presença da fotografia no cenário das artes plásticas, mas também sua conversão em uma espécie de modelo ou paradigma para a arte contemporânea. Aqui, no entanto, interessa apenas chamar a atenção para o fato de que a fotografia prestou-se frequentemente nas artes visuais a uma experimentação com a imagem (e muitas vezes também com a escrita) de si. Artistas como Christian Boltanski, Denis Roche, Cindy Sherman, Nan Goldin ou Sophie Calle, para citar apenas alguns poucos exemplos, fazem uso da imagem fotográfica explorando, de formas diferentes, seja por meio do autorretrato, da autoencenação, da apropriação de fotografias anônimas ou da junção entre texto e imagem, aspectos narrativos, autobiográficos e ficcionais da imagem fotográfica.

No caso de Sophie Calle, o uso sistemático da junção entre texto e imagem, frequentemente a partir de relatos e lembranças pessoais, mas também da promoção de situações e jogos performáticos, e o recurso ao livro (convertido não só em espaço de exposição, mas também em produto de um processo performático e de uma operação de construção e montagem de texto e imagem) permitem situá-la num espaço de cruzamento ou interstício entre práticas artísticas e literárias. Seguindo pessoas na rua (A suivre) ou deixando-se seguir por um detetive particular (La filature), convidando amigos e desconhecidos para dormir em sua cama (Les dormeurs), trabalhando como arrumadeira em um hotel (L'hôtel), telefonando para todos os números anotados em uma agenda de telefones encontrada na rua (Le carnet d'adres$s e s$ ), seguindo uma dieta cromática adotada pela personagem Maria (inspirada na própria artista) do livro Leviatã, do escritor americano Paul Auster (L'obéissance), Calle provoca situações e acontecimentos e os registra, subvertendo o caráter documental do dispositivo fotográfico ao fazer com que ele se volte para a documentação de uma realidade fabricada ou encenada.

O volume Histórias reais (Des histoires vraies), publicado em 1994, é exemplar do cruzamento, operado pela artista, entre fotografia, relato pessoal, performance e prática do livro. O livro é composto por uma série de pequenos fragmentos textuais em primeira pessoa, sempre acompanhados de uma fotografia; trata-se de uma coleção de lembranças pessoais, registros, confissões, pequenas histórias sobre pessoas, objetos e situações (verdadeiros "biografemas"). A maior parte dos textos versa sobre lembranças pessoais, e uma boa quantidade deles começa com uma marcação temporal mais 
ou menos precisa, em que Calle especifica o ano em que o episódio narrado ocorreu ("Foi em 1984...”; "Eu o vi num dia de dezembro de 1985..."; "Conheci-o num bar, em dezembro de 1989..."; "Na terça feira, dia 10 de março de 1992...") ou a idade que ela tinha então ("Eu tinha nove anos..."; "Tínhamos onze anos..."; "Eu tinha quatorze anos..."; "Aos quinze anos..."; “Eu tinha dezoito anos...”; “Eu tinha vinte e sete anos...”). O caráter de registro e evidência, no entanto, é perturbado, tanto no caso dos textos quanto no das imagens, pela parte de encenação, teatro, ritual, jogo e simulação que os atravessa.

Assim, nas fotografias reproduzidas no livro que mostram a própria autora, ela aparece: sobre um palco, apenas de calcinha, com uma peruca loira e um véu negro sobre o rosto jogada no chão, com os olhos fechados, entre uma série de objetos e roupas espalhadas, numa foto que ocupa duas páginas, sob a qual se encontra o relato de como foi atacada por uma colega com um salto agulha e perdeu os sentidos (ficamos nos perguntando quem poderia ter tirado tal fotografia, ou se a foto, como é mais provável, é uma reconstituição); fantasiada com um focinho de porco; de costas, numa fotografia polaroide que a mostra com uma linha vermelha no pescoço; com a cabeça cortada pelo enquadramento, segurando os seios; vestida de noiva, entre um grupo de amigos e familiares, num "casamento de mentirinha" (num episódio em que a "foto de casamento" substitui o casamento em si - "[...] resolvi convidar família e amigos, no sábado, dia 20 de junho de 1992, para uma foto de casamento nos degraus de uma igreja de bairro, em Malakoff'); ${ }^{52}$ mais uma vez vestida de noiva, agora de vermelho, para um casamento que deveria realizar-se na pista do aeroporto, mas para o qua não foi possível obter autorização; de camisola, no alto da Torre Eiffel, onde passou a noite de 5 para 6 de outubro de 2002. Calle subverte desse modo a relação usual entre vida e texto autobiográfico, colocando em prática uma série de ações para que se convertam em narrativa (e em fotografia) (ou ainda, conforme se vê na exposição Doubles-jeux e posteriormente no livro De l'obéissance, realizando de fato - $\mathrm{e}$ registrando - ações que foram atribuídas ficcionalmente a uma personagem de Paul Auster inspirada nela mesma), assumindo uma série de máscaras e disfarces (striper, detetive, noiva, camareira, entrevistadora), embaraçando os laços entre prática artística, vida pessoal e narrativa autobiográfica.

Em um artigo intitulado Les mythologies de Roland Barthes, Sophie Calle et Hervé Guibert, Magali Nachtergael mostra como, mais ou menos na mesma época, Barthes, Guibert e Calle integraram fotografias e relato pessoal, em trabalhos híbridos e frequentemente fragmentários. Nachtergael procura definir essas diferentes práticas narrativas em torno da fotografia a partir da ideia de "mitologia individual".
52. CALLE. Histórias verdadeiras p. 69.
EM TESE
BELO HORIZONTE
v. 21
N. 2
MAID-AGO. 2015
MAROUES. A Fotografia do Jardim de Inverno: Barthes, fragmento, fotografia $\quad$ p. 11-28 
53. Cf. NACHTERGAEL. Les mythologies de Roland Barthes, Sophie Calle et Hervé Guibert.

54. Em 1981, Hervé Guibert escreve L'image fantôme, livro composto por 64 fragmentos textuais que giram em torno da fotografia (o livro não contém, porém, nenhuma reprodução fotográfica). $O$ texto que abre o livro (e que Ihe empresta o título) é o relato de uma sessão em que Hervé fotografa a própria mãe. Durante a revelação, porém, ele se dá conta de que, por um erro de manipulação, as imagens não foram feitas e a sessão está perdida. Trata-se, assim, de um texto sobre uma fotografia ausente, não realizada. Cf. GUIBERT. L'image fantôme. Hervé Guibert é também autor de um livro que justapóe texto e imagem fotográfica, por ele designado como um "romanphoto": Suzanne et Louise, cuja primeira edição é de 1980, reúne uma série de fotografias de duas tias-avós de Guibert, acompanhadas de fragmentos textuais, boa parte dos quais se volta para as próprias sessões de fotografia (numa delas, os três simulam a morte de Suzanne).

55. A trilogia L'absence foi lançada por Calle em 2000; ela é constituída por três livros, que giram em torno de três projetos artísticos desenvolvidos pela autora na década anterior: >>>

A autora ressalta o modo como a inserção desse elemento estrangeiro - a fotografia - no texto vem perturbar as classificações genéricas e impor um outro regime de leitura. Barthes, Guibert e Calle, cada um em um contexto diferente - crítico, ficcional e artístico (mas também explorando os cruzamentos desses campos) -, colocam em cena um dispositivo simultaneamente textual e imagético, em prol de uma reconfiguração do relato pessoal.

Nachtergael nota, apesar das diferenças, algumas similaridades entre os trabalhos dos três autores (artistas que se cruzaram também na vida), ${ }^{53}$ como o recurso à fotografia, a recorrência da associação entre texto e imagem e o gosto pelo fragmento e pelo relato de si (que tende, porém, para a ficção de si). A autora constata, ainda, uma mesma atração pela "fotografia do invisível", seja porque ela é imostráve (como a foto da mãe em Barthes e Guibert), ${ }^{54}$ seja porque ela é ausente ou fantasmática (Hervé Guibert intitulou um de seus livros L'image fantôme; Sophie Calle deu o título de Fantômes a um de seus trabalhos, em que pede a algumas pessoas para descrever e desenhar obras ausentes de museus, trabalho posteriormente incluído em uma trilogia que recebe o nome de L'absence; ${ }^{55}$ Barthes não se cansa de notar o elemento fantasmático da fotografia - Spectrum é o nome que ele sugere dar àquilo que é fotografado, termo que remete a "essa coisa um pouco terrível que há em toda fotografia:

retorno do morto"). ${ }^{56}$ Assim, esses trabalhos híbridos, compostos pela junção de fotos e textos, promovem não apenas uma reconfiguração da escrita de si, que flerta abertamente com a ficção, mas também exploram, como efeito da ausência (ausência da imagem ou imagem da ausência), o caráter fantasmático da imagem fotográfica.

\section{REFERÊNCIAS}

BARTHES, Roland. 0 império dos signos. Trad. Leyla PerroneMoisés. São Paulo: Martins Fontes, 2007.

BARTHES, Roland. A preparação do romance I - da vida à obra. Trad. Leyla Perrone-Moisés. São Paulo: Martins Fontes, 2005.

BARTHES, Roland A câmara clara 2 ed Rio de Janeiro: Nova Fronteira, 1984

BARTHES, Roland. Roland Barthes por Roland Barthes. São Paulo: Cultrix, 1977

BARTHES, Roland. Sade, Fourier, Loyola. Trad. Mário Laranjeira. São Paulo: Brasiliense, 1990

BARTHES, Roland. Sur la photographie. In: Roland Barthes et la photo: le pire des signes. Cahiers de la Photographie, 1990. p. $74-80$

CALLE, Sophie. Histórias reais. Trad. Hortencia Santos

Lencastre. Rio de Janeiro: Agir Editora, 2009.

CALLE, Sophie. Fantômes. Paris: Actes Sud, 2000
BELO HORIZONTE
N. 2
MAIO-AGO. 2015
MARQUES. A Fotografia do Jardim de Inverno: Barthes, fragmento, fotografia P. 11-28
55. > > > Fantômes, Disparitions (Last Seen) e Souvenirs de Berlin-Est. Fantômes se constrói a partir de uma solicitação, feita pela artista, de que funcionários (entre os quais curadores, restauradores e guardas do Museu de Arte Moderna de Paris e do Museu de Arte Moderna de Nova York, que tiveram obras temporariamente emprestadas ou retiradas, descrevessem ou desenhassem as obras ausentes (entre as telas ausentes estão, por exemplo, Nu dans le bain, de Pierre Bonnard, L'assassin menacé, de Magritte e House by Railroad, de Edward Hopper). Também Disparitions (Last Seen) é composto por descrições e desenhos feitos por funcionários do Museu Isabella Stewart Gardmer, em Boston, que teve alguns quadros roubados na década de 1990, e de outros museus que tiveram obras roubadas ou destruídas. Nos dois casos, o livro contém fotografias que mostram as descrições e os desenhos expostos no espaço antes destinado aos objetos emprestados destruídos ou roubados. Já em Souvenirs de Berlin-Est, a artista entrevista habitantes de Berlim a respeito do desaparecimento de monumentos representativos da Alemanha comunista após a queda do muro: o livro inclui, além das descrições dos monumentos ausentes fotografias antigas desses monumentos fotos do spaco vazio deixado após sua retirada.

56. BARTHES. A câmara clara, p. 20 
CALLE, Sophie. Disparitions. Paris: Actes Sud, 2000

CALLE, Sophie. Souvenirs de Berlin-Est. Paris: Actes Sud, 2000.

CALLE, Sophie. De l'obéissance. Paris: Actes Sud, 1998.

DUBOIS, Philippe. $\mathbf{O}$ ato fotográfico e outros ensaios. 10. ed. Trad. Marina Appenzeller. Campinas, SP: Papirus, 1993.

GUIBERT, Hervé. L'image fantôme. Paris: Les Éditions Minuit, 2007.

GUIBERT, Hervé. Suzanne et Louise (Roman-Photo). Paris: Gallimard, 2005.

$\mathrm{HISCH}$, Marianne. Family frames: photography, narrative, and postmemory. Harvard University Press, 1997.

\section{NACHTERGAEL, Magali. Esthétique des mythologies}

individuelles: le dispositif photographique de Nadja à Sophie

Calle. Université Paris-Diderot - Paris VII, Paris, 2010. Disponível

em: < http://tel.archivesouvertes.fr/docs/00/64/08/63/PDF/

Nachtergael_mythologies_individuelles_redux.pdf $>$.

NACHTERGAEL, Magali. Les mythologies individuelles: récit de soi et photographie au 20e siècle. Amsterdam: Rodopi, 2012.

POZUELO YVANCOS, José María. De la autobiografía: teoría y estilos. Barcelona: Crítica, 2006

SONTAG, Susan. A escrita em si mesma: sobre Roland Barthes. In: Questão de ênfase. Trad. Rubens Figueiredo. São Paulo: Companhia das Letras, 2005, p. 88-120. 